HAMID VAHID

\title{
VARIETIES OF EPISTEMIC CONSERVATISM
}

\begin{abstract}
According to the thesis of epistemic conservatism it would be unreasonable to change one's beliefs in the absence of any good reasons. Although it is claimed that epistemic conservatism has informed and resolved a number of positions and problems in epistemology, it is difficult to identify a single representative view of the thesis. This has resulted in advancing a series of disparate and largely unconnected arguments to establish conservatism. In this paper, I begin by casting doubt on the claim of widespread and genuine applications of the conservative policy. I then distinguish between three main varieties of epistemic conservatism, namely, differential, perseverance and generation conservatism Having evaluated various arguments that have been offered or may be considered on behalf of the conservative thesis, I close by concluding that those versions of the thesis that survive critical scrutiny fail to live up to the aspirations of the thesis as a substantive canon of rationality, that to the extent that principles of conservatism are epistemically promising, they are not plausible. While to the extent that they are plausible, they are not of much epistemic interest.
\end{abstract}

It has been claimed that the stability of one's belief system is a cognitive virtue, an end towards which cognitive agents should strive. While sticking dogmatically to one's beliefs is epistemically preposterous, it would be equally unreasonable, it is said, to change them in the absence of any good reasons. This position known as epistemic conservatism seems to have had a distinguished line of advocates among the likes of Quine and Chisholm. It has also been claimed that epistemic conservatism has informed and resolved various positions and problems in epistemology from foundationalist theories of justification to problems such as the underdetermination of theories by data. Looking at the literature on this topic though, it is, however, difficult to single out an account as definitely representing the thesis of epistemic conservatism. Sometimes the thesis is formulated in terms of the requirement that one be justified in holding to a theory even when faced with competing but evidentially equivalent hypotheses. Sometimes it is claimed that merely believing a proposition is sufficient for its justification, and so on. In general, what one finds is that various principles are being employed under the rubric of conservatism often without sufficient attempt being made to establish their credibility beyond mentioning certain pragmatic considerations.

In this paper, I begin by expounding the thesis of epistemic conservatism and its alleged applications. Having shown that the applications in 
question are far from being genuine, I highlight the disparate and largely unconnected attempts that have been made to establish conservatism. The diversity, I shall argue, is mainly due to the fact that the theorists are actually concerned with different and non-equivalent versions of epistemic conservatism. Having distinguished between different varieties of conservatism, I set out to determine their credibility by evaluating various arguments that have been offered or may be considered in their defense. While finding the arguments generally wanting, it is important, I believe, not to opt for a wholesale rejection of the conservative theses as the arguments offered in their defense vary in their structure. The burden of this paper is, therefore, to assess the merit of each argument on its own as it is geared towards establishing a distinct thesis. I close, however, by arguing that those versions of the thesis of epistemic conservatism that survive critical scrutiny fail to live up to the aspirations of the thesis as a substantive canon of rationality.

\section{EPISTEMIC CONSERVATISM AND ITS PURPORTED APPLICATIONS}

According to the thesis of epistemic conservatism, it is unreasonable to subject our belief system to revision or change without any good reasons. Not only would this incur an unnecessary utilization of resources and energy on the part of the cognizer, it would also fail to bequeath the agent's cognitive system any epistemic benefit. Thus, epistemic conservatism views the stability of one's belief system as an epistemic virtue, something that, on certain accounts of the thesis, has survival value and is the product of the optimific process of natural selection. Epistemic conservatism comes in many forms, the most basic of which asserts that the mere possession of a belief confers justification on that belief. So an agent is justified in holding a belief simply in virtue of the fact of holding it.

Although the proponents of conservatism are quick to point out that the epistemic credibility that it bestows on a belief is only prima facie and minimal, one cannot help feeling that there must be something unsatisfactory about a thesis that takes the mere holding of a belief to endow it with epistemic worth. And, in general, would not the conservative policy of encouraging stability and retaining the status quo in one's belief repertoire hinder the course of inquiry by undermining our motivation to break new grounds? The advocates of conservatism, however, reject these charges as being superficial. In turn, they highlight the cases where conservatism has supposedly informed and shaped a number of prominent contemporary philosophical views such as those of Quine's and Chisholm's. ${ }^{1}$ It is further claimed that conservatism helps us to deal with a number of intractable 
quandaries in philosophy such as the problem of the underdetermination of theories by data, the problem of keeping track of the justifications of one's beliefs, and so on. And, as was briefly noted, some even go as far as suggesting an evolutionary story of why it features so prominently among our purported canons of theory choice. It is, they say, a good thing in costbenefit terms that we maintain stability in our belief system. In fact, this is what Nature has designed us to do: "[It] would not want us to change our minds capriciously and for no reason". ${ }^{2}$

Despite such enthusiasm, doubts about the epistemic legitimacy of conservatism linger on. Such doubts become if anything stronger when, on close inspection, one realizes that some of the applications and uses of the conservative policy are rather contrived and superficial than genuine. For example, in some cases the conservative thesis just does not sit well with the views that allegedly exploit it. Conservative principles are primarily principles of justification and reasonableness of holding beliefs and, as such, they seem to be at odds with those views, such as Quine's, that seek to eschew the most distinctive feature of traditional epistemology viz., its normativity altogether replacing it by descriptive psychology. ${ }^{3}$ And sometimes, where a particular conservative principle - as a norm of rationality - is claimed to be at work (as in the case of Sklar's principle), it turns out that what is really doing the job is some disguised form of a holistic coherentism or another theory of justification. To substantiate this claim, I shall examine some of the cases where the thesis of epistemic conservatism is said to be operative.

The first case involves the use of conservatism in dealing with the problem of underdetermination. For the sake of concreteness, I shall focus on Foley's account of the story. ${ }^{4}$ According to Foley some philosophers suggest that when confronted with a number of incompatible but otherwise equivalent hypotheses, "it is more rational for a person to believe the hypothesis which conflicts with the smallest number of his beliefs than to believe the other hypotheses". ${ }^{5}$ What lies behind the legitimacy of this advice, he claims, is the thesis of epistemic conservatism: "As far as I can see, if such questions are to be given a fully epistemic answer, it must be in terms of a principle similar to the [conservative] principle which Chisholm endorses". 6 The principle says "anything we find ourselves believing may be said to have some presumption in its favor - provided it is not explicitly contradicted by the set of other things that we believe". 7 But that cannot be the whole story. As I shall explain later, Chisholsm's principle is just one expression of the thesis that takes the bare fact of holding a belief to confer justification on that belief. As such, the principle would be of no help in deciding which of the hypotheses to believe. For, by 
assumption, all competing hypotheses are evidentially equivalent and (by Chisholm's principle) should enjoy an equal degree of presumption in their favor. Rather, what seems to be doing the work, in Foley's account of the story, is the appended consistency condition to the principle requiring the new belief not to induce an explicit contradiction in the cognizer's belief repertoire. So one can see Foley's suggested policy in regard to choosing between evidentially equivalent hypotheses as really being underpinned by a straightforward consistency requirement, rather than a conservative principle like Chisholm's, to the effect that one should minimize inconsistency in one's belief system when deciding to add new beliefs. Moreover, it would be quite futile to try to implement the policy if it turns out that all the competing hypotheses are equally consistent with our background beliefs.

Foley's other example of the use of epistemic conservatism involves a position, called 'Maximalism', which he attributes to Goldman, and takes it to be in conformity with the Quinean conception of epistemology. Foley quotes Goldman on the nature of Maximalism: "It invites us to employ all our antecedent beliefs whenever we wish to appraise our cognitive methods. A Maximalist argues that there is likely to be little or no basis for choice among methods unless we employ a prior corpus of belief. And if some prior beliefs are allowed, why not allow them all". ${ }^{8}$ However, unless we assume that these prior beliefs which cognizers happen to hold "have some favorable epistemic status" themselves, they cannot be used in the appraisal process of their cognitive methods. But to assume this, says Foley, is to involve the thesis of epistemic conservatism for we are, in effect, assuming that those prior beliefs acquire their favorable epistemic status in virtue of being held by the cognizers.

But this is not really a good example of epistemic conservatism in action, for Foley quotes only part of what Goldman says about Maximalism. Maximalism would indeed presuppose conservatism if the "prior corpus of belief" had its epistemic worth conferred on it only in virtue of being held by the agent. But Goldman is quite explicit about the source of justification of these prior beliefs. They owe their positive epistemic status to the fact that they are adequately grounded or reliably produced. Immediately after the last sentence in the above quote, Goldman goes on to delimit the scope of allowable prior beliefs by adding the following qualifiers: "Or at least the more confidently held among them, or those arrived at by methods which, until now, we regard as most reliable? Given the present state of science, we have a rich set of beliefs about the physical world. According to Maximalism, all this information can legitimately be used in commending new cognitive strategies, or appraising the ones we have". ${ }^{9}$ Goldman 
contrasts Maximalism with Minimalism, a position that holds that "the appraisal and choice of cognitive procedures should antecede acceptance of scientific beliefs, and hence must not appeal to any such beliefs". ${ }^{10}$ So it is quite clear that the prior corpus of belief that, according to Goldman, should be employed in the appraisal of cognitive methods consists mostly of scientific beliefs and, in general, beliefs that are obtained reliably. It is because of the way these beliefs are produced or obtained that they enjoy favorable epistemic status and not because of the bare fact that they are held by agents. Regardless of whether it is an epistemically credible position, Maximalism does not presuppose epistemic conservatism.

The preceding remarks are not intended to count as a wholesale denial of the epistemic utility of the thesis of epistemic conservatism. Perhaps some versions of the thesis can have some legitimate application in our cognitive practices. But they should, at least, admonish us against describing it as an overarching strategy in our cognitive endeavors. However, what compounds the problem is that discussions of the thesis tend to switch back and forth between what seem to be different and often non-equivalent versions of the thesis of epistemic conservatism. Apart from the ensuing confusions, this makes it difficult to ascertain the validity of the arguments that have been suggested in its defense, for an argument that is designed to defend one version of the thesis may turn out to be quite irrelevant to the validity of another. My aim in the rest of this paper is, therefore, to isolate different varieties of epistemic conservatism and evaluate their merits individually on their own.

\section{VARIETIES OF EPISTEMIC CONSERVATISM}

Looking at the literature on epistemic conservatism, one is struck by the various guises under which the thesis of conservatism appears. Sometimes we see a theorist adopting a differential attitude, choosing to focus on one version of conservatism to the exclusion of others, and sometimes we see another theorist taking all versions on board implying that what he says about one version is equally true of others. In neither case, however, is any attempt made to explain the uniformity of the adopted methodology or its lack thereof. Here are some examples.

In an early statement of the thesis of epistemic conservatism, or 'methodological conservatism' as it is called there, Sklar opens his remarks by dismissing what he regards as a strong version of the thesis according to which "the very fact that a proposition is believed can serve as warrant for some attitude to be rationally maintained in regard to believing it". ${ }^{11}$ Instead, he opts for a more "modest" principle of methodological 
conservatism which requires us not to reject a hypothesis once believed just because we come to know of an evidentially equivalent alternative to it. This is also the line that is taken by both Vogel ${ }^{12}$ and Adler ${ }^{13}$ in their discussions of epistemic conservatism. By contrast, Chisholm articulates and makes use of a variant of the version of epistemic conservatism that Sklar had earlier rejected for being too strong.

Gilbert Harman initially defines conservatism as the view that a proposition can acquire justification simply by being believed, but officially defends a version of conservatism according to which "one is justified in continuing fully to accept something in the absence of a special reason not to". ${ }^{14}$ (He gives a slightly different but closely related formulation of conservatism when expounding his Principle of Positive Undermining.) William Lycan, on the other hand, mentions all the aforementioned theses under the rubric of epistemic conservatism, and seems to think that they are all legitimate although, for the most part in his discussion, he focuses on what he calls the 'Principle of Credulity' according to which one is required to accept at the outset propositions that seem to be true. ${ }^{15}$ Likewise, David Christensen, ${ }^{16}$ to give one last illustration, declares that the thesis of epistemic conservatism takes many forms and claims, without offering an argument, that all these forms share the basic idea that the mere fact of believing a proposition confers some justification on that proposition.

As the preceding remarks show, one is faced with many and often seemingly non-equivalent versions of the thesis of epistemic conservatism. This is not just because of the fact that some theorists are keen to accept one version of the thesis to the exclusion of others, but also because the arguments that are adduced to substantiate epistemic conservatism are usually tailored towards defending one specific version of the thesis and are ineffective to support others. So in order to evaluate the feasibility of epistemic conservatism, it would be necessary to isolate different varieties of conservatism. I think one can discern three types of conservative principles.

$\begin{array}{ll}\text { Generation conservatism (GC) } & \begin{array}{l}\text { Holding a belief is sufficient for its } \\ \text { justification. }\end{array} \\ \text { Perseverance conservatism (PC) } & \begin{array}{l}\text { One should stop believing a propos- } \\ \text { ition whenever one positively be- } \\ \text { lieves one's reasons for believing } \\ \text { that proposition are no good. }\end{array} \\ \text { Differential conservatism (DC) } & \begin{array}{l}\text { One is justified in holding to a hy- } \\ \text { pothesis (belief) despite coming to } \\ \text { know of evidentially equivalent al- } \\ \text { ternatives. }\end{array}\end{array}$


GC can be particularly associated with Chisholm while PC and DC have been respectively defended by Harman and Sklar. In what follows, I shall evaluate (in reverse order) the credentials of each of these principles in the light of the arguments and considerations that have been offered in their favor.

\subsection{Differential Conservatism}

DC has been prominently defended by Sklar. As was just noted, he begins his discussion of epistemic conservatism by considering what we have called the principle of 'generation conservatism' and dismisses it as being too strong for it would seem to have the consequence that any belief whatsoever could be deemed as rational. Sklar, thus, opts for "more modest" principles of conservatism whose distinguishing mark, he says, is that they are not actually concerned with positive warrant for a belief, but, rather, with its justificatory status once it is held. He offers the following principle as truly reflecting the content of the thesis of methodological conservatism which is just a long-winded version of what we have called 'differential conservatism' DC.

(DC) If you believe some proposition, on the basis of whatever positive warrant may accrue to it from the evidence, a priori plausibility, and so forth, it is unreasonable to cease to believe the proposition to be true merely because of the existence of, or knowledge of the existence of, alternative incompatible hypotheses whose positive warrant is no greater than that of the proposition already believed. ${ }^{17}$

Sklar immediately notes the difference between DC and GC, saying that DC "does not commit us to the believability ... of a proposition merely because it is believed .... All it commits us to is the decision not to reject a hypothesis once believed simply because we become aware of alternative, incompatible hypotheses which are just as good as, but no better than, that believed". ${ }^{18}$ This means that the evidential source of a belief in DC is different from that which is specified in GC viz., the bare fact of holding that belief.

Is DC warranted? Before turning to this question, let us consider a commonly made objection (initially due to Goldstick ${ }^{19}$ ) that is intended to call into question the coherence of DC. According to DC if an agent believes $p$ on the basis of evidence e, he is justified in believing that $p$ despite coming to recognize that an incompatible hypothesis, $\mathrm{q}$, is equally supported by e. Now, consider two individuals coming to believe $\mathrm{p}$ and q respectively on the basis of evidence e. By DC they are both justified 
in their beliefs despite the beliefs being incompatible, and this, says the objection, is absurd. Sklar, however, denies that there is anything absurd about this, and gives the example of two societies that are organized on different social systems that serve equally well in bringing about identical social ideals. Under these circumstances, he says, there is no need to change one system and replace it by another. However, as Sklar recognizes, this is not a particularly good analogy as the notion of "correctness" (i.e., truth or falsity) is not really applicable in the case of alternative political systems and this may be said to be responsible for the coherence of the idea of their coexistence. Not so in the case of alternative but evidentially equivalent hypotheses. He thus offers a different analogy much closer to home. Consider a case where two agents form incompatible beliefs on the basis of different observational evidence. There is no doubt that they can be both rational. Sklar goes on to conclude that "if it is logically coherent to maintain that two parties who differ in their evidence can both be rational even though their beliefs are incompatible, then it is logically coherent to maintain that they are equally rational in their incompatible choices even though their different warrant for their beliefs is based solely on the fact that they do believe different incompatible hypotheses and each adopts a principle of conservatism which tells him not to change his belief unless there is some reason to do so". ${ }^{20}$

But this argument is not compelling. For, to begin with, Sklar cashes out the notion of the "evidential source of a belief" in terms of the conservative principle GC whose credibility he had rejected earlier as when he describes the warrant for beliefs as being "based solely on the fact that [the agents] do believe different hypotheses". Moreover, it is not at all clear why the coherence of maintaining the rationality of incompatible beliefs in the case where those beliefs are based on different observational evidence should be equally carried into the case where incompatible beliefs are based on the same (type of) evidence. One way to bring out the dissimilarity between the two cases is to assume the so-called conjunctive principle according to which if evidence e justifies two propositions (beliefs), then it justifies their conjunction. Now, this principle clearly leads to absurdity in the case where incompatible beliefs are assumed to be based on the same evidence, but has no application in the case where incompatible beliefs are based on different evidence. In any event, regardless of the validity of the conjunctive principle, the resemblance of the two cases (vis-à-vis their coherence) is what we are supposed to show rather than assume.

However, I go along with Sklar in maintaining that there is nothing absurd about two incompatible beliefs being equally rational. ${ }^{21}$ But perhaps that is not what lies behind the above objection to DC. Indeed, it 
seems to me that the underlying worry is that DC contravenes the thesis of epistemic supervenience according to which the justification of a belief supervenes on certain non-epistemic properties of that belief (e.g., being part of a coherent belief system, being reliably produced, being adequately grounded, etc.). This would mean that when two beliefs share the same subvening property and one is justified, so is the other. Suppose now two scientists $S_{1}$ and $S_{2}$ who, faced with the task of explaining the same data, come up with incompatible but evidentially equivalent hypotheses $\mathrm{H}_{1}$ and $\mathrm{H}_{2}$ respectively. Suppose further that the hypotheses in question become known to both some time later during a meeting where $\mathrm{S}_{2}$, for some reason of his own, gives up $\mathrm{H}_{2}$ and follows $\mathrm{S}_{1}$ in believing $\mathrm{H}_{1}$. Now, according to DC, $\mathrm{S}_{2}$ should have stuck with $\mathrm{H}_{2}$. His belief that $\mathrm{H}_{1}$ is, thus, unjustified while $S_{1}$ is justified in believing $\mathrm{H}_{1}$ and rejecting $\mathrm{H}_{2}$. So, assuming that $\mathrm{DC}$ is normatively correct, we are faced with a situation in which while believing $\mathrm{H}_{1}$ is rational (justified) for $\mathrm{S}_{1}$, another token of the same belief fails to be rational (justified) for $S_{2}$ despite the two tokens sharing the same subvening justification-conferring property, and this contravenes the thesis of epistemic supervenience.

Further on in his discussion, Sklar speculates that perhaps those who are wary of conservatism are actually reacting to its apparent "arbitrariness", for DC seems to require one to prefer the first-born hypothesis to others. But any of the alternatives could have had that status and this introduces an implausible degree of arbitrariness into our canons of rationality. Sklar dismisses this objection. We would not reject Newton's inference to his theory of spacetime as irrational, he says, because it was the data involving absolutely accelerated objects that first caught his attention and not the results of Michelson-Morely experiment which were not yet available. But this example is one where the adopted hypotheses are prompted by different rather than the same evidence. Given Newton's evidence, his inference to his spacetime theory was quite rational and non-arbitrary. But the objection seems to be concerned with cases where the hypotheses' competition to attain the rationality status is decided solely on the basis of the fact that which one is the first-born despite both being evidentially on a par.

It seems to me that what lies behind the worry that Sklar discusses can, once again, be spelled out in terms of the violation of the supervenience constraint on the notion of rationality (justification). To see this we should not construe 'arbitrariness' in temporal terms, in terms of the time of inception of a hypothesis. Rather, if our account of the failure of supervenience in the context of differential conservatism is correct, what the worry seeks to accentuate is that conservatism has the consequence that like cases fail to be treated alike. That is, with the failure of epistemic supervenience, we are 
prepared to ascribe the property of justification to one belief while refraining from treating another belief as justified despite both beliefs sharing the same subvening justification-conferring property, and this introduces an element of arbitrariness into our canons of rationality.

Now, leaving aside the implausible consequences of differential conservatism, what can be said in its favor? The first thing to note is that DC is lacking in intuitive plausibility. The idea is that when an agent, say a scientist, proposes a hypothesis $\mathrm{H}_{1}$ to account for a set of available data, and it then comes to light that another alternative $\mathrm{H}_{2}$ is equally capable of explaining the data, this revelation should, intuitively speaking, shake the scientist's confidence in her hypothesis. Under the new circumstances, she is no longer entitled to give the same credence to $\mathrm{H}_{1}$ that she initially awarded it. The availability of an alternative should, at least, give her a pause. It would be quite irresponsible of her to go on to develop her theory and completely ignore the alternative explanation in her research. ${ }^{22}$ Let us now turn to the arguments that have been proposed in support of DC.

The first type of argument is of a pragmatic nature, and it is broad enough to cover all varieties of the conservative thesis. Both Lycan and Sklar offer such arguments (though Sklar does not give it much weight). The idea, in a nutshell, is that changing one's mind for no good reason is a waste of time, effort and resources on the part of the cognizer. So adhering to conservatism is a good thing because it saves the energy and effort that would be wasted in changing one's mind. This argument suffers from the weakness of all pragmatic arguments when they are intended to make an epistemic point. Adhering to conservatism may be a good thing from the point of view of saving energy and resources, but what we are interested in (in this context) is whether it is a good thing from the epistemic point of view of maximizing truth and minimizing falsity in one's body of belief. Pragmatic considerations, however, do not speak to such concerns. Lycan realizes this problem but his attitude towards the concept of epistemic justification is quite ambivalent and equivocal. First he acknowledges that he is not "suggesting that our customary canons of theory-preference [which includes conservatism] are epistemically justified by the adaptive utility of our habit of using them". ${ }^{23}$ This raises the expectation that he will have something positive to say about why the thesis is epistemically justified. But he goes on to state that "[c]onservatism as a canon of theory-preference has no justification in the epistemological sense". ${ }^{24}$ I conclude, therefore, that, as far as epistemic justification of DC is concerned, pragmatic considerations fail to lend it any support. Let us then turn to non-pragmatic defenses of differential conservatism. 
One such argument for DC has been offered by Sklar. He bases his defense on a model of epistemic justification he calls the 'local theory of justification' according to which all epistemic justification is relative to a body of an assumed, unchallenged background belief. He thinks this precludes foundationalism with its postulated ultimate beliefs that require no reference to other beliefs for their justification because there cannot be any global justification of our beliefs taken "all at once" - I think Sklar's reasons here trade on the ambiguity between "being justified" in holding a set of beliefs and the "activity of justifying" those beliefs, but we can safely ignore this point for our purposes here. The local theory of justification, however, raises the specter of a problem that is usually associated with coherence theories of justification: There can be incompatible total belief structures all equally rational from the point of view of local justification. To thwart such a possibility, Sklar invokes differential conservatism which requires us to stick with what we have despite becoming aware of competing alternatives (in this case total belief structures). As Sklar himself points out, this argument is of a transcendental type seeking to show that "without conservatism there could be no rational belief at all".

Sklar's argument, however, is unsuccessful. For it has either to assume the version of conservatism GC, that Sklar himself rejects, or else let the local theory of justification collapse into the (holistic) coherence theory of justification. Either way, it fails to establish DC. Consider the first horn of the dilemma. According to the local theory of justification, "we justify the beliefs we take to be in need of justification "one at a time" using all the resources of our unchallenged background beliefs in the process". But this immediately gives rise to the following problem. These background beliefs must themselves have some epistemic worth in order to justify the target belief, and the question is how they acquire their positive epistemic status. With the rejection of foundationalism, these beliefs cannot be the basic beliefs of the foundationalist. One way of getting round this problem is to invoke the generation version of conservatism GC according to which beliefs acquire positive epistemic status merely in virtue of being believed in so far as there is no good reason against them. And this is roughly how Sklar justifies the use of background beliefs: "We are warranted in using them to decide upon the acceptance and rejection of new hypotheses only because their own status is at the time not under scrutiny or challenge". ${ }^{25}$

To avoid this horn of the dilemma, Sklar might choose to say that the background beliefs acquire their epistemic status just like the rest of the members of the agent's corpus of belief viz., by belonging to a coherent belief system. Opting for this alternative, however, makes the local theory of justification collapse into a (holistic) coherence theory of justification 
according to which beliefs acquire their justification in virtue of belonging to coherent belief system. And it is no wonder that Sklar finds himself compelled to tackle the alternative coherent systems objection that is usually raised in the context of coherence theories of justification. But by taking this route, Sklar's argument is stripped of its transcendental character, thus, failing to establish DC. For now, the invoking of DC is not the only way of retorting to the alternative systems objection as there are a number of coherentist responses available to such challenges. ${ }^{26}$ Let us now turn to another variety of conservatism, namely, what I have called, 'perseverance conservatism' (PC).

\subsection{Preseverance Conservatism}

According to PC one is justified to continue to hold a belief as long as there are no good reasons against it. PC is most explicitly defended by Harman. ${ }^{27} \mathrm{He}$ considers it in the context of his theory of reasoned belief revision, and his guiding light in the course of his discussion is the phenomenon that may be called 'lost justification'. The idea is that people do not usually keep track of the justification relations among their beliefs. It so happens that many of an agent's beliefs are such that although they were initially based on adequate evidence, and, thus, justified, the agent subsequently forgets what that evidence was. We have all had experiences in which we justifiably form a belief about something on the authority of some source even though we no longer remember the source despite having retained the belief. This failure to keep track of one's justifications is thought to be a natural consequence of the limitations of our memories and, in general, our brain. There is a limit to the set of things one can store or retrieve. This cognitive failing seems to explain the phenomenon that cognitive psychologists call 'belief perseverance in the face of evidential discrediting'. Well-documented experiments have shown that people tend to retain many of their beliefs despite having been informed of the inadequacy of their original evidential source. The reason for the perseverance is said to be the fact that they no longer remember what the evidential source of their belief was, that the discredited evidence was the reason that prompted the belief in them in the first place.

Harman claims that the fact that people fail to keep track of the justifications of their beliefs (i.e., the phenomenon of lost justification) directly impinges on our arbitration between two main competing theories of belief revision viz., the foundations theory and the coherence theory, thus, allowing us to determine the viability of epistemic conservatism. According to foundations theory one is justified in continuing to believe a proposition if one has a special reason to continue to hold that belief, while on the 
coherence theory one is so justified in the absence of any special reason to change it. It is clear that on the foundations theory one ought to keep track of one's original reasons for one's beliefs if one is to be justified in them, whereas no such requirement is needed in the case of the coherence theory. It seems that the foundations theory is normatively implausible because, given the phenomenon of lost justification, it would imply that people are unjustified in almost all their beliefs. Harman concludes that it is the coherence theory that is normatively correct. He identifies the normative elements of the foundations and coherence theories respectively in terms of the following principles. ${ }^{28}$

Principle of positive under- One should stop believing $\mathrm{p}$ whenever mining (PPU) one positively believes one's reasons for believing $\mathrm{p}$ are no good.

Principle of negative undermining (PNU)

One should stop believing $\mathrm{p}$ whenever one does not associate one's belief in $\mathrm{p}$ with an adequate justification.

As was pointed out, given the phenomenon of lost justification, it is PPU rather than PNU that is correct, Harman argues. Harman further points out that this result supports epistemic conservatism because, unlike the foundations theory, the coherence theory is a conservative principle, for it requires change in one's belief system only if there is a special reason to do so. (PPU is in fact what we have called 'perseverance conservatism' (PC).)

I shall now turn to the question whether Harman's argument succeeds in showing that it is PPU that is the correct normative principle of belief revision, or, to put it differently, whether it commits us to epistemic conservatism as he claims. The first thing to find out is which version of conservatism is purportedly supported by Harman's argument from lost justification. Harman himself is not quite clear what kind of conservative principle he has in mind. He initially construes conservatism as the view that "a proposition can acquire justification simply by being believed". ${ }^{29}$ This shows that it is generation conservatism GC that he has in mind. Later on, however, he offers a different formulation of the thesis. According to the principle of conservatism, he says, "one is justified in continuing fully to accept [believe] something in the absence of a special reason not to". ${ }^{30}$ This is more or less equivalent to PPU which we have called the 'perseverance conservatism'. In fact Harman's latter construal of epistemic conservatism turns out to be identical to another formulation of PPU that he offers in a later part of his book: "[A] principle of positive undermining takes any current belief to be justified as long as there is no special reason to give it up". ${ }^{31}$ 
So, as far as exegetical considerations are concerned, the type of conservative principle that Harman seems to associate with his favored theory of belief revision is, despite occasional lapses, perseverance conservatism PC (i.e., PPU. In fact it is easy to see that generation conservatism GC is inconsistent with the considerations he adduces to support the coherence theory of belief revision. Why? According to GC mere believing of a proposition renders it justified. Now, if the bare fact of holding a belief were to constitute a source of justification for that belief, then there would be no room for the phenomenon of lost justification. For as long as an agent holds a belief, that belief remains justified. There would be no way the agent could lose track of the justification of her belief as long as mere believing is allowed to constitute the source of the justification of that belief. So, consonant with exegetical considerations, generation conservatism cannot be what Harman's argument from lost justification seeks to establish. Let us now see how the argument fares vis-à-vis the principle of perseverance conservatism PC. To answer this question, consider the following concrete example (due to Christensen).

Suppose I currently believe that the population of India is greater than that of the US, remembering to have learnt it from some source though I no longer recall what it was. According to PC, I am justified in continuing to believe this proposition in the absence of undermining evidence. David Christensen has argued that one can explain the reasonableness of maintaining this belief without invoking epistemic conservatism. To explain, he gives a somewhat similar example where an appeal to conservatism is intuitively unattractive. Suppose I flip a coin which lands out of my sight. Without going over to look, I decide that it has landed "tails" up. Intuitively speaking, the fact that I now believe the coin has landed "tails" up does not justify me in maintaining my belief that it has landed tails up. What, then, is the difference between these two cases? According to Christensen, "[i]n both cases, I have a belief for which I am unable to cite any grounds .... Yet in one case, maintaining the belief seems quite reasonable; while in the other, ... unreasonable". ${ }^{32}$ The difference, he says, can be accounted for in a way that also shows why the invoking of conservatism is not needed in the India case. The idea is that in the case of my belief about the population of India, I have some other beliefs to persuade me that the belief in question is accurate despite my forgetting its original evidential source. These beliefs include, among others, the belief that I initially formed my belief about the population of India on the basis of some reliable source, that, despite India being a common topic of family conversation, I have not yet encountered contradictory evidence, etc. These background beliefs constitute the reason for maintaining my belief about 
India's relative population size. But, says Christensen, these are precisely the kind of beliefs that are absent in the coin case which explain why I am not justified in continuing to believe that the coin has landed "tails" up.

However, Christensen's argument fails on several counts. To begin with, his argument is actually targeted at the generation version of conservatism as is made clear by the structure of his coin example and his query whether, in that case, mere believing is sufficient for the justification of the belief that the coin has landed "tails" up. But, as I have emphasized, it is perseverance conservatism that is the target of Harman's argument from lost justification. Secondly, the coin case is not really analogous to the India case. It is true, as Christensen says, that "in both cases, I have a belief for which I am unable to cite any grounds", but in the coin case this statement owes its truth to the fact that there are no grounds to cite, not that there are grounds but I have now lost track of them. My belief that the coin has landed "tails" up, unlike my belief about the population of India, is completely ungrounded and this is something that I know.

Moreover, the India case is not really pertinent to Harman's argument, for it is not a case in which an agent loses track of the justifications of his belief by failing to recall its evidential ground. Given Christensen's way of setting up the example, I know enough about the evidential ground of my belief regarding India's population to render it justified. I know, among other things, that "I was once told by my mother, or a teacher, or some other reliable source, and I (quite rationally) accepted the source's word for it". ${ }^{33}$ What seems to be lacking, then, is just my knowledge of who told me this, my mother, John or Jane. But surely the name or identity of my source would be irrelevant to the justification of the belief in question. The belief was not, say, that "My mother told me that India is more populous than the US" so that the case described would count as one where justification is lost. Rather, the belief in question is about the relative size of India's population, and what we know about its origin is quite sufficient to render it justified. So this is not a genuine case where one's justification for a belief is lost. For the example to count as pertinent to Harman's argument, it is essential that the original evidential source be genuinely lost. Suppose, a few years ago, I read in The Guardian that India is more populous than the US. I then justifiably formed a belief about India's population. Suppose I still retain the belief but no longer recall the original evidential source. Nevertheless, it is still justified because it was acquired in an epistemically proper manner, and that is exactly what PC maintains. ${ }^{34}$

To provide further support for the above contention, recall that Harman uses the fact of losing track of one's justification to explain the "phenomenon of belief perseverance in the face of evidential debriefing" where, 
as studies seem to show, agents still hold on to their beliefs despite being told that their (original) evidential source was inauthentic: "They continue to believe things after the evidence for them has been discredited because they do not realize that the discredited evidence was the sole reason why they believe as they do. They do not see they would not have been justified in forming these beliefs in the absence of the now discredited evidence". ${ }^{35}$ Now, surely, in Christensen's example, if there were to be a debriefing, the agent would no longer persist in his belief about India's population. Once he is told that, for example, he got his belief from an unreliable source, then he would give the belief up. This further shows that Christensen's India example is not really pertinent to Harman's argument.

So we are still left with the question whether Harman's argument from lost justification show that his brand of epistemic conservatism, i.e., PC, is normatively correct. One thing that Harman's argument effectively shows is that, given the phenomenon of lost justification, the foundations theory of belief revision is not normatively correct. It shows, in other words, that it is not the case that one should stop believing a proposition whenever one does not associate one's belief in that proposition with an adequate justification i.e., that PNU is false. But to show that PNU is false is not, ipso facto, to show that PPU - i.e., PC - is true. In fact, PPU seems also to be undermined by the phenomenon of lost justification. According to PPU, one should stop believing a proposition whenever one positively believes one's reasons for believing that proposition are no good. But this requires, at least, that one should be able to recall one's reasons for a belief, something which seems to be at odds with the phenomenon of lost justification. ${ }^{36}$ However, as I noted, Harman is not quite consistent when formulating PPU or his considered version of the conservative thesis. Sometimes, he formulates it in a way that is no longer susceptible to the above problem as when he says that "according to the principle of positive undermining, one is justified in continuing to believe a proposition as long as there is no special reason to give it up". Is this modest version of PC plausible?

To answer this question, let us recall that Harman's perseverance brand of conservatism concerns cases where an agent is initially justified in believing a proposition but later loses track of her reasons. It is necessary that the agent be initially justified in her belief, for otherwise one could hardly make sense of her losing track of the justification of that belief. Thus, assuming that people generally fail to keep track of the justifications of their beliefs, it would be reasonable to continue to hold them provided there is no undermining evidence. So this version of PC is plausible, but it is questionable whether it really deserves to be seen as canon of rationality 
(in virtue of being a conservative principle) as it seems that one may explain its plausibility by invoking certain innocuous assumptions about the concept of epistemic justification.

To see this, we may begin by assuming that "being justified" is an objective property of a belief which, as we noted, supervenes on certain non-epistemic (but equally objective) properties of that belief (e.g., being adequately grounded, being reliably produced, etc). We may also distinguish between "being justified" in holding a belief and the "activity of justifying" that belief, assuming that one can be justified in believing a proposition without being able to show that one is so justified, just as one can be said to have a moral virtue without being able to show that one is in possession of that virtue. ${ }^{37}$ In the light of these assumptions, it would be plausible to maintain that if an agent is initially justified in holding a belief but later loses track of her reasons, the belief in question remains justified, or, to put it differently, she remains justified in holding that belief (provided, of course, that the justification in question is not undermined by her cognitive state at any time ${ }^{38}$ ). The agent's losing track of the grounds of her belief does not affect the fact that the belief was initially prompted by adequate justification-conferring grounds and, thus, came to instantiate or possess the property of justification. What it does affect, however, is that, under the new circumstances, the agent is no longer able to show that she is justified in holding the belief in question, but, as was emphasized, performing the latter task is not a necessary condition of the agent's being justified in holding that belief. We can thus view our modest version of PC as being underpinned by certain plausible assumptions regarding the concept of justification rather than drawing on some general idea of epistemic conservatism. Let us now turn to our third and final version of epistemic conservatism.

\subsection{Generation Conservatism}

While the two varieties of conservatism we have considered so far are concerned with the justificatory status of a belief after its conception and acquiring positive epistemic value, generation conservatism GC, as the name implies, is concerned with the initial stage of a belief-forming process where the produced belief comes to acquire its epistemic worth. In this sense GC is the most fundamental type of epistemic conservatism. In its most widely used formulation, it says that a proposition acquires positive epistemic status simply by being believed by an agent. But, as we have seen, GC has also been regarded as the most controversial version of epistemic conservatism, even by those who are favorably disposed towards other varieties of the conservative thesis. 
Despite its controversial character, however, a number of theorists have defended some version of GC. Lycan, for example, has advocated a version of GC, which he calls the 'Principle of Credulity', according to which one should "accept at outset each of those things that seem to be true". 39 Another version has been endorsed by Chisholm who proposes it as an assumption that has to be made if one is construct a viable foundationalist theory. Chisholm's principle seems to be the most promising version of generation of conservatism as it is intended to avoid the over-permissive character of the original formulation, and will thus be, for the most part, the focus of my attention in this section. As we have mentioned repeatedly, part of theorists' ill disposition towards GC is the ease with which it allows any belief to pass as rational. In order to avoid this consequence, Chisholm qualifies $\mathrm{GC}$ by requiring that the mere believing of a proposition endow it only with some presumption of rationality: Anything we find ourselves believing may be said to have some presumption in its favor (provided it is not explicitly contradicted by the set of other things that we believe). On Chisholm's construal, GC occupies the lowest epistemic level in the hierarchy of justification; “'Certainty' [constitutes] the highest degree of epistemic justification and 'having some presumption in its favor' the lowest" ${ }^{40}$ Chisholm's characterization of 'reasonability' in terms of the "general requirement to try to have the largest possible set of logically independent beliefs which is such that the true beliefs outnumber the false beliefs" 41 is precisely how "justification" is generally understood in terms of the aim of maximizing true beliefs in one's belief system.

I think, however, that Chisholm's principle should be qualified along one further dimension in order to provide a tighter safeguard against the problem of over-permissiveness. GC tended to make the justification of a belief independent of the fact that beliefs are responsive to the cognizer's environment and the world in general. This would then allow any belief that a cognizer happens to hold (irrespective of how it is acquired) as possessing some rationality. Consequently, we may qualify GC along the following lines: Any proposition an agent comes to believe as a response to his (relevant) environment has some presumption of rationality (provided it does not explicitly contradict the rest of what he believes). But even this version of GC is far from being ideally clear as it fails to provide us with an account of the boundaries of the notion of rationality it involves. So the thesis needs some filling out. However, before attending to this task, I wish to examine some objections of Foley's which are intended to demonstrate that even this modest version of GC is too strong. ${ }^{42}$

Foley's general strategy is to propose certain test cases through which he hopes to highlight some of the implausible consequences of Chisholm's 
version of GC. As an example, he considers a case where an agent $\mathrm{S}$ comes to believe a proposition $\mathrm{h}$ (not explicitly contradicted by the set of his beliefs) whereas, given his circumstances, it is more reasonable for him to believe its negation (not-h). According to Foley such cases are surely possible though they are ruled out by Chisholm's conservative principle which he describes in the following terms: "[I]f $\mathrm{S}$ believes $\mathrm{h}$ and $\mathrm{h}$ is not explicitly contradicted by anything else $S$ believes, then proposition $\mathrm{h} . .$. is a proposition which is more reasonable for $\mathrm{S}$ to believe than to disbelieve". ${ }^{43}$ But this objection is not convincing. First a dialectical point. Foley's example need not be taken as discrediting Chisholm's principle. For we can consider the principle, as described by Foley, as a norm of reasoning and belief formation (a canon of rationality), and regard the agent's knowledge of such norms as constituting his reasoning competence. We can then make a distinction between performance error and competence error i.e., between mere mistakes or lapses and systematic violations of the norms in question. Nothing in what Foley says shows that the type of case he mentions is a systematic and persistent phenomenon (he describes it as a "possible" situation). We may then say that such divergences from the norm are performance error, and not really indicative of the agent's reasoning competence failing to match those norms. Of course this is a large task, but the point is that, even if one concedes the coherence of Foley's cases, there are ways of redescribing them that may leave the coherence of the corresponding norms intact.

Moreover, one may ask, in Foley's example, what makes not-h more reasonable for $\mathrm{S}$ to believe than $\mathrm{h}$. This might be the case because not-h is better supported by S's total evidence, but then we are assuming that $\mathrm{S}$ has in his possession some independent evidence which supports not$\mathrm{h}$ rather than $\mathrm{h}$. If so, then there would be no need to apply Chisholm's principle for it is a principle that concerns cases where an agent's justification in believing a proposition has its source in the bare fact of its being believed by that agent. If, on the other hand, we are not assuming that $S$ has independent evidence that favors not-h, then, on pain of begging the question against Chisholm, it is not clear how not-h is more reasonable for $\mathrm{S}$ to believe than $\mathrm{h}$. This is a charge that Foley himself recognizes might threaten his arguments: "Constructing [those] counterexamples does not amount to constructing a non-question begging argument against conservative positions". ${ }^{44}$ These considerations are also pertinent to Foley's other counterexamples. Given the basic nature of the principle of generation conservatism, the most promising procedure for its evaluation is, I think, to try to draw the contours of the notion of rationality it involves, for it is only then that one would be able to judge whether it really lives up to 
the expectations that a principle of conservatism, as a canon of rationality, generates. Here is how I propose to do this.

It seems to me that the following considerations, involving Davidson's principle of charity, can be used to lend some support to Chisholm's principle, and concurrently reveal its epistemic potentials through giving content to the notion of rationality it aspires to invoke. A theory of meaning, on Davidson's account, is a Tarski-style truth theory that for each object language sentence (s) gives a metalanguage sentence (p) which is true if and only if that object language sentence is true. Such T-sentences (as they are known) provide the truth conditions (meaning) of the object language sentence. Thus when an interpreter finds a sentence of the speaker which the speaker assents to regularly under conditions he (the interpreter) recognizes, he takes those conditions to be the truth conditions of the speaker's sentence. ${ }^{45}$ The idea is to recover the meaning of the speaker's utterances from the environmental circumstances that prompt them. But this is, by no means, a straightforward feat.

Very roughly, Davidson takes the evidence for the semantic theory to consist in the conditions under which speakers hold sentences true. This however turns out to be a function of both what the sentence means as well as what the speaker believes which, in turn, gives rise to the problem of interdependence of belief and meaning. It would thus be quite unwarranted to take the circumstances under which a sentence is assented to as giving the truth conditions (meaning) of that sentence. It is at this point that the principle of charity enters the scene. To get out of the impasse, the interpreter has to assume that the speaker perceives her environment roughly as he does and, consequently, comes to form similar beliefs. This is what grounds the necessity of the principle of charity in getting the process of interpretation going. ${ }^{46}$ We can solve the problem of interdependence of belief and meaning, says Davidson, "by holding belief constant as far as possible while solving for meaning. This is accomplished by assigning truth conditions to alien sentences that make native speakers right when plausibly possible, according, of course, to our own view of what is right $"{ }^{47}$ The principle of charity, thus, requires the maximization of truth by the interpreter's own lights. It requires, in other words, the interpreter to maximize agreement between himself and the speaker by assigning to her the same type of beliefs as his.

Now, if belief ascription is constrained by the principle of charity, then this goes some way towards supporting our qualified version of GC. For, as was emphasized, the process of charitable belief ascription is characterized by the aim of maximizing truth and minimizing falsity in the speaker's belief system, which is actually how epistemic justification is generally 
characterized, namely, in terms of the aim of the maximization of truth and minimization of falsity in an agent's body of belief. ${ }^{48}$ So once belief ascription is seen as constrained by the principle of charity, this would automatically provide some "presumption of rationality" for the ascribed belief which is precisely what generation conservatism claims. Note that the distinction between the belief ascriber and the believer is not really epistemically significant in the context of our discussion. Charity begins at home. The interpreter's beliefs are as much subject to the constraint of charity as are the beliefs of the interpretee.

Now, to what extent are the ascribed beliefs rational, or, to put it differently, what notion of rationality is at work in the case of belief ascriptions to speakers. I said that the charity constraint on belief ascription provides the belief in question with some "presumption of rationality". The use of the quoted phrase was deliberate, as I wanted to use the very term that had appeared in Chisholm's formulation of generation conservatism. But, given the mechanism of the interpretive process, we can now be more precise about its content and import. It was initially thought that the principle of charity has significant epistemological ramifications for once it is granted that beliefs are interpretable, then it would be hard to avoid the conclusion that they are generally correct, or, at least, objectively justified. However, as we saw, all that the principle of charity requires is maximization of truth by the interpreter's own lights, and, for all we know, the interpreter's beliefs might be mistaken.

So, in a sense, in the course of the interpretive process we do not seem to be leaving the web of belief. Of course, these beliefs might be true, but this is not what the argument from interpretation guarantees. (It is for this reason that Davidson appends the argument from charity with two loosely related strategies, now widely thought to be unsuccessful, viz., the invoking of the idea of an omniscient interpreter and a particular brand of externalism about the nature of belief to give the argument some epistemic bite. ${ }^{49}$ ) All that can be deduced from these considerations is that the kind of rationality that results from the interpretive process is rationality-fromthe-point-of-view-of-the-agent (taking the interpreter and the interpretee to be one and the same person), a conception of rationality that emphasizes the agent's own perspective and how things appear from that perspective. On many accounts of epistemic justification (rationality) this is a weak and subjective notion of rationality that is not necessarily a good indicator or means to truth. ${ }^{50}$ This is consonant with Chisholm's claim that his generation principle occupies the lowest level in the hierarchy of justification. I do not, however, wish to get myself entangled in the debate over what the right conception of rationality is. My point is rather that if we take the 
charity constraint on belief ascription to underwrite the thesis of generation conservatism, then the epistemic limitations of the principle of charity will equally determine the epistemic strength of the conservative thesis itself in drawing the boundaries of the notion of rationality it involves.

In the light of the preceding remarks, it would be safe to say that to the extent the thesis of generation conservatism is plausible, it is of limited epistemic potential. This is also true of Lycan's version of GC, namely, the principle of credulity, according to which the seeming plausibility (truth) of beliefs is sufficient for their acceptance. This principle renders, what Lycan calls, 'spontaneous beliefs' (i.e., beliefs not inferred from other beliefs but produced by such sources as perception, memory, etc) prima facie justified. ${ }^{51}$ This is an interesting and substantial epistemic principle. But just when the conservative thesis begins to look interesting, Lycan weakens it to make it plausible. He realizes that his principle, indiscriminately, warrants both, what he calls, 'lovable' as well as 'wild' spontaneous beliefs with the former category involving perceptual, memory beliefs, etc., while the latter category is supposed to include religious, superstitious beliefs and the like. To exclude wild spontaneous beliefs, he imposes a number of constraints on his principle of credulity: Logical consistency and consistency with previously justified explanatory beliefs. But he also requires that our total body of beliefs and theories be able to provide an explanation of how the spontaneous belief in question was produced in us.

Although the above constraints might be able to exempt wild spontaneous beliefs from the reach of the principle of credulity, the resulting conservative principle faces, at least, two problems. First there is the problem whether these constraints can be satisfied even in the case of the so-called 'lovable' spontaneous beliefs. Consider the first two consistency constraints. Lycan is not ideally clear about their import. He seems to require that we should be able to determine whether such beliefs are consistent with other spontaneous beliefs as well as with all "previously justified beliefs or with explanatory beliefs conjoined with other spontaneous beliefs". ${ }^{52}$ But given the size of these background beliefs and in view of our so-called 'finitary predicament' ${ }^{53}$ - limitations of our cognitive resources - this is a rather daunting task to perform. And in any case, the consistency of an agent's set of beliefs may not be accessible to that agent even on careful reflection (recall, as an example, Frege's acceptance of the axioms of the Basic Laws).

Secondly, it is not quite clear whether Lycan's third "explanatory" constraint is really able to rule out, what he regards as, 'wild' spontaneous beliefs. For consider someone who claims to have received direct communications from heaven. Surly, he does possess, on the basis of his total 
body of beliefs, an explanation of how the spiritual beliefs were produced in him. ${ }^{54}$ Indeed, Lycan goes on to admit that " $[\mathrm{t}]$ here are many interesting border line cases here", 55 and he includes logical intuitions and religious beliefs among them. This further erodes the value of his conservative principle as a substantive canon of rationality (at least, by his lights). Moreover, the imposition of Lycan's third constraint runs the risk of reducing his conservative norm to a variant of the more familiar standard of rationality viz., the reliability norm. Given an spontaneous belief, he requires that our "total body of beliefs and theories yield an idea of how that spontaneous belief was produced in us - perhaps even a mechanical explanation of how it was. Finally suppose that according to this idea or explanation, the mechanism that produces the belief was (as we say) a reliable one, in good working order. Then, I submit, our spontaneous beliefs are fully justified" ${ }^{56}$ Although he says he does not require the believer to have a full knowledge of "the reliable mechanism", he maintains that the agent should "be aware of the source of the belief and recognize that the source is a generally trustworthy one". ${ }^{57}$ But now his principle of credulity now seems too close to a version of the reliability account to count as an independently legitimate and substantial conservative thesis. ${ }^{58}$

As our investigation shows certain plausible versions of PC and GC survive critical scrutiny. However they are epistemically very modest, falling short of the aspirations of the thesis of epistemic conservatism as a substantive canon of rationality. To conclude, to the extent that principles of conservatism are epistemically promising, they are not plausible. To the extent that they are plausible, they are not of much epistemic interest.

\section{ACKNOWLEDGEMENTS}

I would like to thank Tim Williamson and a referee of this journal for helpful comments on earlier drafts of this paper.

\section{NOTES}

1 See Quine (1951) and Chisholm (1980).

2 Lycan $(1988,161)$.

3 Here, of course, I am referring to Quine's views in 'Epistemology Naturalized'. There have been other versions of naturalistic epistemology that recognize and try to incorporate the distinctive features of traditional epistemology. However, since it is Quine who is usually cited as one of the most prominent advocates of epistemic conservatism, I am focusing on his views. Other, more acceptable, versions of naturalistic epistemology usually distinguish themselves by taking causes of beliefs as being relevant to their justification. 
It would be interesting to note that another prominent advocate of conservatism, namely, Chisholm, rejects the causal approach in favor of erecting standards of justification for beliefs that have no place for their causes. Perhaps the more interesting question in the context of epistemic conservatism is what naturalism commits one to.

4 Foley (1982).

5 Ibid., 166.

6 Ibid.

7 Chisholm (1980, 551-552).

8 Goldman (1979, 29-30).

9 Ibid., 30.

${ }^{10}$ Ibid., 29.

11 Sklar $(1975,375)$.

12 Vogel (1992).

13 Adler (1990).

${ }^{14}$ Harman (1986, 46).

15 Lycan (1986).

16 Christensen (1994).

17 Sklar (1975, 378.

18 Ibid.

19 Goldstick (1971).

20 Sklar $(1975,385)$.

${ }^{21}$ Lycan concurs. He also thinks that there is nothing wrong in saying that two agents with the same evidence can both be justified in believing conflicting hypotheses.

${ }^{22}$ For the same line of thought on the intuitive plausibility of DC see Vogel (1992) and Adler (1990).

${ }^{23}$ Lycan $(1986,159)$.

24 Ibid., 166.

${ }^{25}$ Sklar $(1975,398)$

${ }^{26}$ Christensen places Sklar's argument in the context of the skepticism debate, and objects to it on the ground that - in the case of alternative coherent systems objection - the skeptic is challenging the whole corpus of the conservative agent's beliefs (including conservatism itself). He concludes that it would therefore be question-begging to invoke conservatism in response to such a skeptic. But, as I have characterized Sklar's argument, the alternative systems problem is an offshoot of Sklar's local theory of justification rather than arising in connection with the thesis of global skepticism.

${ }^{27}$ Harman (1986).

28 Ibid., 39.

29 Ibid., 30.

${ }^{30}$ Ibid., 46.

${ }^{31}$ Ibid., 117.

32 Christensen (1994, 74).

33 Ibid., 73.

${ }^{34}$ It might be suggested that one may have a background belief according to which most of what one remembers was learned in an epistemically proper manner. Would that be sufficient to justify the belief about India's population? As Goldman (1999) says, this evidence is not sufficient for justification, for if I had learnt the belief from, say, a local 
unreliable newspaper, then, even given that background belief, I would not be justified in holding the belief. The way I learned the belief is still relevant and decisive.

35 Harman (1986, 38).

${ }^{36}$ I thank a referee of this journal for pressing me to clarify this point.

${ }^{37}$ For this distinction see various articles in Alston (1989).

38 This is, of course, equivalent to Goldman's non-undermining condition that he rightly thinks is necessary for a belief's justification. He mentions a number of ways in which a belief's permittedness may be undermined. See Goldman (1986, 62-63).

${ }^{39}$ Lycan $(1988,165)$.

${ }^{40}$ Chisholm (1980, 547).

41 Ibid., 546.

42 Foley (1982) and (1987).

43 Foley $(1982,173)$.

44 Ibid., 179.

45 Assuming that compositionality and other relevant constraints are also satisfied.

${ }^{46}$ In fact Davidson regards the principle of charity as having such a primary status that he takes it as being constitutive of the psychological realm. If the concepts of belief, desire, etc., are not applied in accordance with the principle of charity, there is no reason, he says, to take them as applying at all.

${ }^{47}$ Davidson (1984, 137).

48 To cite just one example: "Epistemic evaluation is undertaken from what we might call the "epistemic point of view". That point of view is defined by the aim of maximizing truth and minimizing falsity in a large body of beliefs" (Alston 1989, 83).

${ }^{49}$ See Vahid (2001) for discussion.

${ }^{50}$ See, for example, Goldman (2001).

51 Lycan (1988, Chap. 8).

52 Ibid., 167.

53 Cherniak (1980).

54 I owe this point to a referee of this journal.

55 Lycan $(1988,169)$.

56 Ibid, 168.

${ }^{57}$ Ibid., 169.

${ }^{58}$ When referring to the reliability of belief-forming mechanisms in elaborating the explanatory constraint, it is quite obvious that Lycan has Goldman-type reliability theories in mind. For he explicitly mentions Goldman's account and says that "[e]ven if my theory of the initial justification of ultimate explainees eventually fails, we could always fall back on a straightforward reliability account, since our ultimate explainees tend to be the very sorts of beliefs for which a reliability theory works well" (172). This remark further supports my claim that, with the added constraints, Lycan's conservative norm looks increasingly like a variant of the familiar reliability norm.

\section{REFERENCES}

Adler, J.: 1990, 'Conservatism and Tacit Confirmation', Mind 99, 559-570.

Alston, W.: 1989, Epistemic Justification, Cornell University Press, Ithaca, NY. 
Cherniak, C.: 1986, Minimal Rationality, MIT Press, Cambridge, MA.

Chisholm, R.: 1980, 'A Version of Foundationalism' in Wettstein, et al (eds), Midwest Studies in Philosophy V, University of Minnesota Press, Minneapolis, MN.

Christensen, D.: 1994, 'Conservatism in Epistemology', Nous 28, 69-89.

Davidson, D.: 1984, 'Radical Interpretation', reprinted in Inquires into Truth and Interpretation, Clarendon, Oxford.

Foley, R.: 1982, 'Epistemic Conservatism', Philosophical Studies 43, 165-182.

Foley, R.: 1987, The Theory of Epistemic Rationality, Harvard University Press, Cambridge, MA.

Goldman, A.: 1979, 'Varieties of Epistemic Appraisal', Nous 13, 23-38.

Goldman, A.: 1986, Epistemology and Cognition, Harvard, Cambridge, MA.

Goldman, A.: 1999, 'Internalism Exposed', The Journal of Philosophy 96, 271-293.

Goldman, A.: 2001, 'The Unity of Epistemic Virtue' in Fairweather and Zagzebski (eds), Virtue Epistemology, Oxford University Press.

Goldstick, D.: 1971, 'Methodological Conservatism', American Philosophical Quarterly 8, 186-191.

Harman, G.: 1986, Change in View, MIT Press, Cambridge, MA.

Lycan, W.: 1988, Judgement and Justification, Cambridge University Press.

Sklar, L.: 1975, 'Methodological Conservatism', Philosophical Review LXXIV, 186-191.

Quine, W. V. O.: 1951, 'Two Dogmas of Empiricism', in From a Logical Point of View, 2nd edn., Harper \& Row, New York.

Vahid, H.: 2001, 'Charity, Supervenience, and Skepticism', Metaphilosophy 32, 308-325.

Vogel, J.: 1992, 'Sklar on Methodological Conservatism', Philosophy and Phenomenological Research 52, 125-131.

Department of Philosophy

Bilkent University

Ankara, Turkey

E-mail: vahid@ipm.ir 